the astronauts' preparations. Beyond their efforts, the technical analysis for the mission took months; the political determination proved equally difficult. Accelerating the preparation for launch, with more than 150,000 people fully involved in the process, represented a management challenge as arduous as any ever taken by NASA.

Apollo 8's second claim to fame is one of the most significant photographs of the twentieth century, Earthrise, snapped by Anders from lunar orbit (see go.nature. com/2ne4zai). It shows the Moon, grey and lifeless in the foreground, with Earth awash in colour in the blackness of space. Earthrise symbolized an emerging environmental consciousness for more than a generation. In a remarkable understatement, Kluger concludes that it "would eventually move people to understand that worlds - like glass - do break and that the particular world in the photograph needed to be cared for more gently than humans had ever treated it before".

He might have included some of the expansive commentary on this image by the astronauts, or responses from poets and pundits, preservationists and potentates. Instead, he emphasizes that the astronauts did not guess that the portrait, taken on 24 December, would be so influential - the ultimate reconnaissance photograph of Earth from afar. (Kluger does pay due attention to a Christmas Eve broadcast in which the crew read from Genesis, striking a rather heroic tone.)

Kluger closes Apollo 8 with a touching story that Borman has told repeatedly. This hinges on the events that made 1968 one of the most tumultuous in US history, from North Korea's capture of the surveillance ship USS Pueblo to the Tet Offensive of the Vietnam War, the assassinations of civil-rights icon Martin Luther King Jr and presidential hopeful Robert F. Kennedy, and widespread rioting over racism. The success of the mission seemed to many US citizens balm for an open wound. Borman recalled receiving a telegram that said, “Thank you, Apollo 8. You saved 1968."

That triumphalist story is symptomatic of Kluger's emphasis. Historian Alex Roland has called such accounts "tribal rituals, meant to comfort the old and indoctrinate the young". He is right. But rituals serve a purpose. That is why most readers will enjoy the vicarious thrill of that flight to the Moon in the stellar company of Borman, Anders and Lovell.

Roger Launius retired last year as associate director of the Smithsonian Institution's National Air and Space Museum in Washington DC, and is now principal of Launius Historical Services. e-mail:launiusr@gmail.com

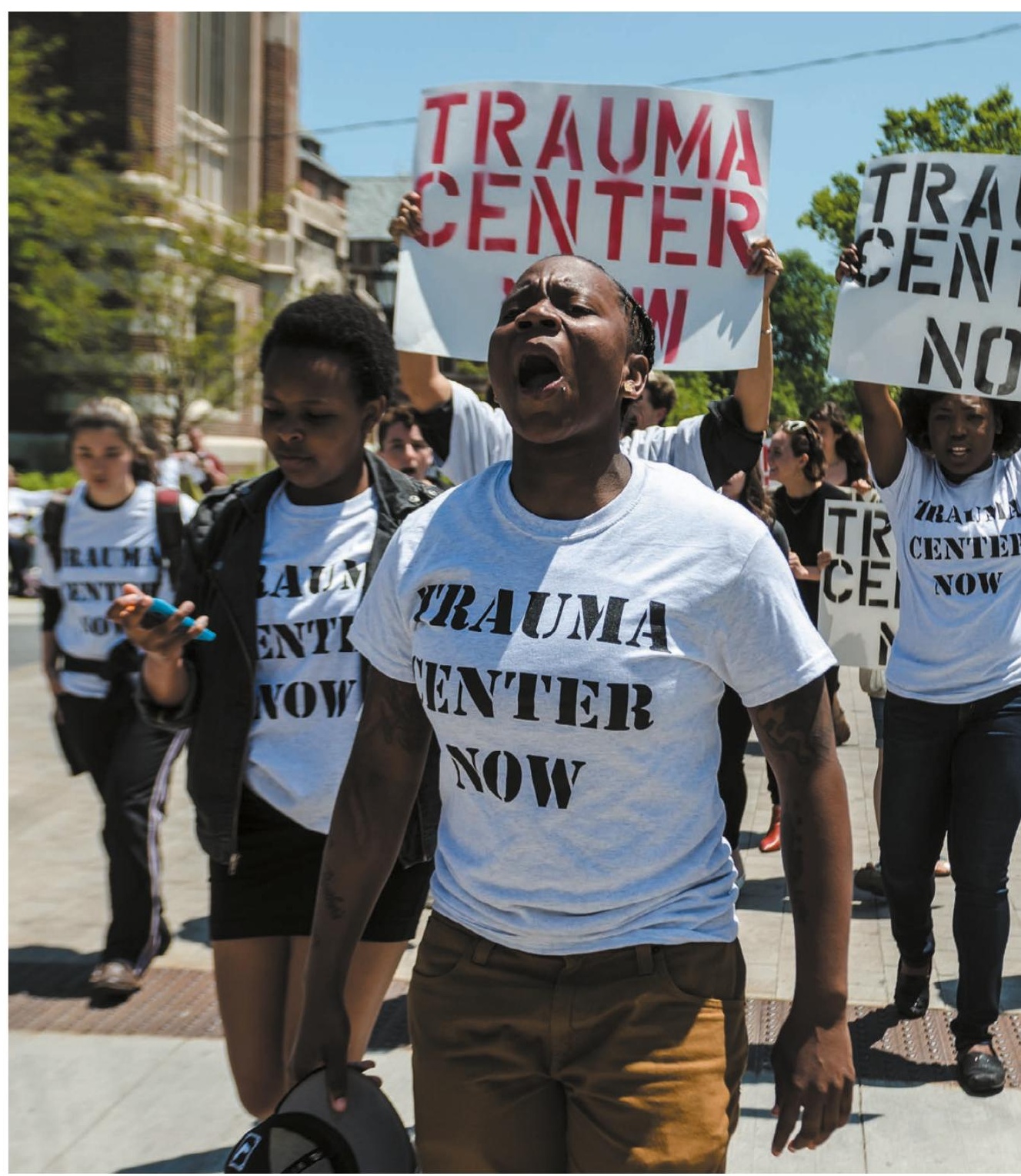

Protestors hold a rally against the lack of an adult trauma centre at the University of Chicago Hospital.

\title{
INEQUALITY
}

\section{Live poor, die young}

\section{Abigail A. Sewell examines a physician's study of how deprivation shortens lifespan.}

$\mathrm{D}$ avid Ansell's passionately written The Death Gap presents a powerful case for social inequality as a cause of disease and disparities in health. The social epidemiologist, physician and public-hospital veteran invokes the concept of 'death gaps' to describe differences in life expectancy by race, ethnicity, class and geography.

Ansell uses an approach that is gaining traction in health and medicine, casting health disparities in the United States as arising from the commodification and politicization of health care. He sees the country's health system as another form of structural violence - harm resulting from unjust social systems, such as poor-quality housing and emergency infrastructures. This architecture, anchored by racism, classism and placeism (discrimination on the basis of neighbourhood), fosters ill health in the most marginalized and vulnerable groups, such as poor black people in urban areas and rural working-class white people. For the most unfortunate, such assaults on 


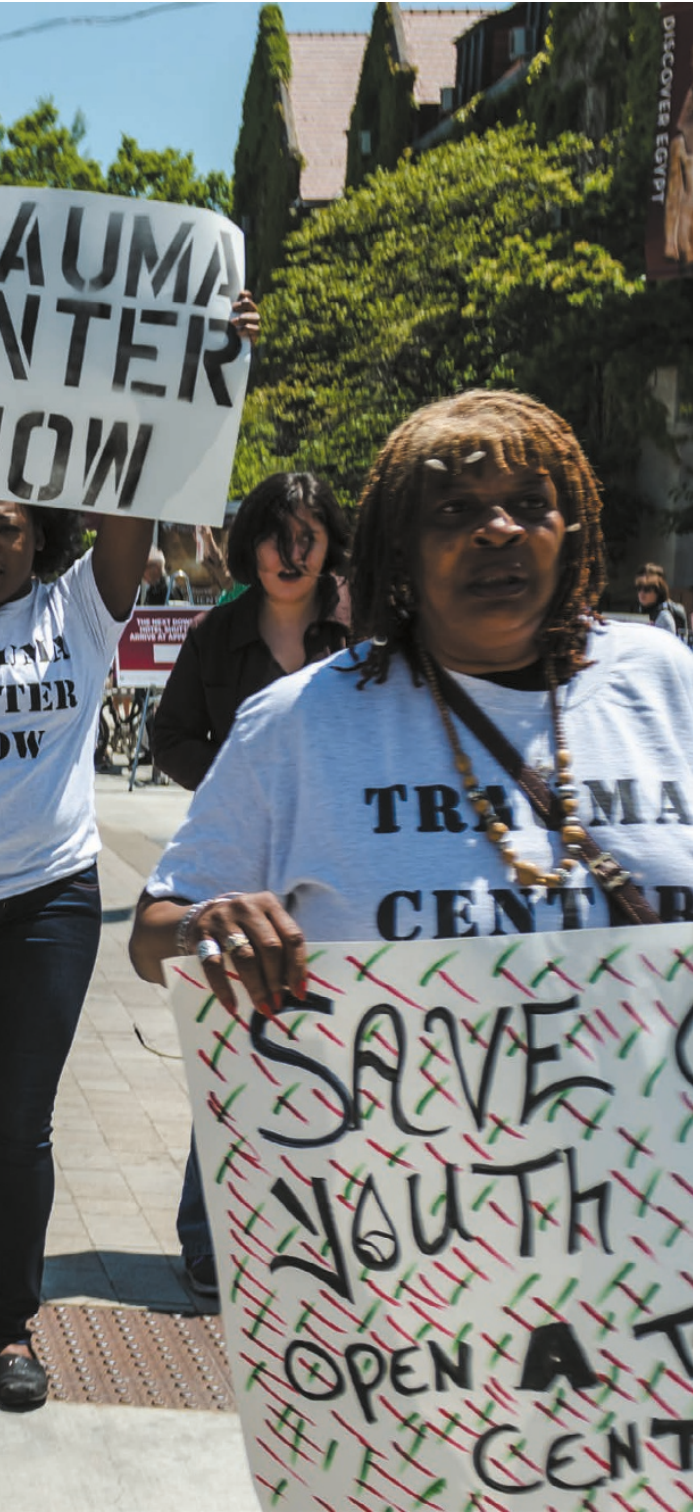

\& health status shave away decades of life. As Ansell shows, there is as much as a 35-year difference in life expectancy between the healthiest and richest US neighbourhoods and the most ill and deprived.

The Death Gap lays out general concepts that inform the complex web of structural violence through case studies and synthetic analyses. Ansell invites us into the heartwrenching story of one of his long-term patients, whose deprived circumstances led to a disability-inducing stroke - a condition rigged, he argues, by the power and dynamics of public policies that cultivate social inequality. Citing the case of a survivor of Haiti's catastrophic 2010 earthquake, he questions the medical practice of recording cause of death according to the illnesses that precipitate decline, rather than the long-term social conditions that place people at risk of

ONATURE.COM For more on science in culture see: nature.com/ booksandarts

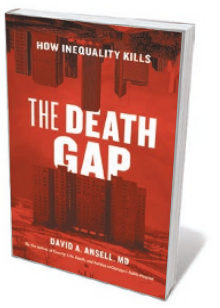

The Death Gap: How Inequality Kills

DAVID ANSELL Univ. Chicago Press: 2017. risk. And he looks at 'property politics' in relation to race, seeing it as a key mechanism that perpetuates social, political and economic inequality. The same exploitative processes, he argues, affect disadvantaged black people in inner cities, rural white people and reservation-bound indigenous Americans.

Ansell lays the blame for inequalityrelated damage to health on ideologies that absolve the wealthy of responsibility and motivation for advocating for an equitable society. He also points the finger at how the US health system and some areas of medical research ignore the interplay between life circumstances and health. Income inequality and neighbourhood stressors - such as ambient noise, proximity to highways, exposure to violence and low social cohesion - have an impact, he shows, on biological processes that accelerate ageing and break down the body's ability to fight disease. As the basis for these inferences, Ansell cites the growing body of research that links stress to the length of telomeres - caps on chromosomes whose degeneration is associated with shortened lifespan and age-related illnesses.

He also examines how stringent policing policies such as 'stop and frisk', which arose in the post-civil-rights era to control newly empowered black people, adversely affect mental health and family ties that protect well-being. And he reminds us how inequality deepens the impact of natural disasters such as the 1995 heat wave in Chicago, Illinois, which killed more than 700 people, and the devastation of much of New Orleans, Louisiana, by Hurricane Katrina in 2005. As these cases show, disproportionate numbers of deaths and displacements occur in black communities when public and health-care safety nets fail.

Ansell's road map for achieving health equity is partly based on the successes he perceives as emanating from health-care activism among poor, ethno-racially vulnerable populations in Chicago. For example, after a year of community-instigated demonstrations, hunger strikes and meetings with hospital administrators, the Illinois legislature agreed to more inclusive laws concerning organ transplants for undocumented kidney patients. After the introduction of qualitycontrol measures for breast-cancer screening (pushed by the Metropolitan Chicago Breast Cancer Task Force), the city witnessed a $35 \%$ reduction in mortality disparities between black and white women. And local activists were instrumental in highlighting the geographical maldistribution of adult trauma care in Chicago after the shooting of community leader Damian Turner in 2010 on the impoverished South Side.

Turner's case is structural violence in action. He was killed by a stray bullet from a drive-by shooting less than half a kilometre from the University of Chicago Hospital, which had closed its trauma centre owing to budgetary concerns years before. He died after arrival at the nearest trauma centre, 16 kilometres away. Community organizers led sit-ins at the University of Chicago Hospital, prompting academic studies that characterized Chicago as a "trauma care desert". Finally, the university conceded, establishing such a centre at its hospital for the first time in more than two decades.

At the federal level, the 2010 Affordable Care Act (ACA, known as Obamacare) receives a searing critique. Ansell lambasts its reliance on a tiered insurance system, recommending instead universal 'single-payer' health-insurance systems like those in Can-

"There is
a 35 -year
difference in
life expectancy
between the
richest US
neighbourhoods
and the most
deprived."
ada and Taiwan. But despite ongoing issues with the ACA and its putative replacements, Ansell is optimistic. Citing community responses to the 2008 financial crisis, he shows how neighbourhood unity can act as a buffer against the negative effects of structural violence. In the final chapter, he extols the transformative capacity of his medical peers and the community, and reveals how it is possible to change US health care from a privilege to a right.

The Death Gap presents a Marxian view of inequality as a societal disease that in turn produces biological disease, dispersed differentially across the sociopolitical hierarchy. Although he is a physician, Ansell uses metaphorical language that may stump readers in biomedical fields. Moving beyond epidemiological frameworks that model what would happen to an individual exposed to a single causal factor, Ansell weaves a much more complicated story, in which structures of disadvantage affect every step of the process of survival. The Death Gap provides an overarching framework for understanding the root cause of ethno-racial and economic disparities in illness that seamlessly weaves together the very best research in epidemiology, public health, medical sociology, health policy and psychology.

Abigail A. Sewell is a sociologist at Emory University in Atlanta, Georgia, focusing on racial disparities in health and medical care. e-mail:abigail.a.sewell@emory.edu 